\title{
PROPAGAÇÃO POR ESTAQUIA SEMILENHOSA DE Inga fagifolia (L.) Willd. Ex Benth. (INGÁ) COM USO DE FITOREGULADOR
}

\author{
Claudiana Moura dos Santos ${ }^{1}$, Paula Maria Marroquim², Laurício Endres ${ }^{*}$ \\ ${ }^{1}$ Centro de Ciências Agrárias, Universidade Federal de Alagoas, BR 104 Norte, Km 85, Rio Largo, AL. \\ ${ }^{2}$ Bióloga, Secretaria Municipal do Meio Ambiente, Rua Marquês de Abrantes, s/n, Bebedouro, 57018-655, Maceió, AL. \\ "Autor para corespondência: Laurício Endres, endres@pq.cnpq.br.
}

\begin{abstract}
RESUMO - O Ingá [Inga fagifolia (L.) Willd. Ex Benth.] é uma árvore nativa da Mata Atlântica. Tem sido usado na restauração da mata ciliar. $O$ presente trabalho teve como objetivo avaliar os efeitos dos fitoreguladores ácido indolbutírico (AIB) ou ácido naftalenoacético (ANA) e do inibidor da ação do etileno tiossulfato de prata (STS) sobre 0 enraizamento de estacas de ingá. Foram montados três experimentos em delineamento fatorial. No primeiro foram utilizadas três concentrações de STS $(0 ; 0,5$; e 2,0 mM) e quatro de concentrações AIB $(0 ; 12,50$; 25 e $50 \mathrm{mM}$ ). No segundo a fonte de auxina foi trocada por ANA. Ambos feitos na época úmida. $O$ terceiro experimento foi igual ao primeiro somente feito na época seca. Após tratadas, as estacas foram transferidas para uma câmara úmida, com 120 dias, foram avaliadas as porcentagens de estacas sobreviventes, formação de calo, enraizamento, número de raízes por estaca, comprimento de raízes e retenção foliar. Os resultados mostraram que o ácido indolbutírico (AIB) em todas as doses testadas inibiu o enraizamento. $O$ ácido naftalenoacético (ANA) até a concentração de 50mM não teve efeito sobre o enraizamento. Doses acima de 0,5 mM de STS na ausência de auxina foram mais eficientes no enraizamento de estacas, talvez por aumentar a retenção foliar, o qual deve ser considerado como base para novos estudos envolvendo propagação por estaquia. A época mais favorável, para a estaquia correspondeu ao mês de maio (época chuvosa).
\end{abstract}

Palavras chave: Propagação vegetativa, ácido indolbutírico, ácido naftalenoacético e tiossulfato de prata.

\section{PROPAGATION OF INGA FAGIFOLIA BY ROOTED CUTTING WITH GROWTH REGULATORS}

ABSTRACT - Inga (Inga fagifolia (L.) Willd. Ex Benth.) is a native tree from Atlantic Rainforest of Brazil. It has been used in agroforest systems to recovering of river marginal forests. The purpose of this study was to evaluate the effects of indolebutyric acid (IBA) or naphthalene acetic acid (NAA) and ethylene action inhibitor, silver thiosulphate (STS), on rooting of stem cuttings. A factorial design was utilized on the two experiments. At the first one, three STS (0; 0,5 and 2,0 mM) and four IBA concentrations (0; 12,50; 25 and $50 \mathrm{mM}$ ) were used. At the second one, auxin was changed to NAA. Both experiments were mounted during the wet season. The third experiment was the same as the first but mounted during the dry season. The cuttings were placed on rooting substrate in green house with intermittent mist. After 120 days, they were evaluated to percentage of alive cuttings, callus formation, adventitious root formation, roots per cutting, length of root and leaf retention. The results showed that IBA in all concentrations tested inhibit root formation. Concentration up to $50 \mathrm{mM}$ of NAA had no effect on roots per cutting. Dose over 0.5 $\mathrm{mM}$ of STS in absence of auxin were more effective root formation, maybe by increasing leave retention, which should be consider for further research in cutting propagation. The most favorable season for cutting propagation is the wet season.

Key words: vegetative propagation, indolebutyric acid, naphthalene acetic acid, silver thiosulphate.

\section{INTRODUÇÃO}

O ingá [Inga fagifolia (L.) Willd. Ex Benth.], pertencente à familia Leguminosae-Mimosoideae, é uma planta típica de matas úmidas situadas em várzeas, tanto primárias como secundárias; no Brasil, ocorre desde a Amazônia até o Nordeste (Lorenzi, 2004). É também amplamente distribuído nos demais países da América Latina e Caribe, em especial México, Venezuela e Antilhas, onde vem sendo 
estudada sua importância econômica (Francis et al., 1994). O interesse pelo cultivo desta espécie está relacionada à arborização urbana, sombreamento de cafezais na América Central, na restauração da mata ciliar e uso da madeira para caixotaria, lenha e carvão (Lorenzi, 2004). Além de ser uma planta com potencialidade para fixar nitrogênio, suas flores são fonte importante de néctar para as abelhas, seus frutos são comestíveis e muito apreciados pela fauna (Little et al., 1964; Francis et al., 1994).

A propagação do ingazeiro é feita principalmente por semente. As sementes de ingá têm a sua qualidade fisiológica reduzida acentuadamente quando sua umidade apresenta-se abaixo dos $40 \%$, culminando com a total perda de viabilidade (Lopes et al., 2002). Estudos mostram que a viabilidade destas sementes, assim como as de outras espécies do gênero, é muito curta, em geral não ultrapassando 15 dias em condições naturais (Oliveira \& Beltrati, 1993). Segundo Lorenzi (2004), as sementes perdem a viabilidade ao secar, havendo a necessidade de sua germinação imediatamente após a retirada das vagens para produção de mudas.

Por outro lado, a produção de mudas por clonagem tem algumas vantagens sobre a reprodução sexuada, garantindo a seleção de genótipos superiores, além da maior produção de mudas em menor espaço de tempo (Donadio et al., 1992; Neves et al., 2006). Muitos trabalhos têm sido desenvolvidos sobre a propagação vegetativa por estaquia em razão da necessidade de mudas em viveiros comerciais. Outra vantagem bastante interessante e a produção de mudas ao longo do ano independente da disponibilidade de sementes. A estaquia é uma prática agronômica que visa retirar ramos de uma planta adulta e forçar o enraizamento dos mesmos, culminando com a produção de uma planta nova (Hartmann et al., 1997; Martins et al., 2001). Em muitas espécies, o sucesso dessa técnica somente é possível por meio da manipulação das condições ambientais e fisiológicas, as quais propiciam a dediferenciação dos tecidos, e, finalmente, a formação de raízes adventícias.

A manipulação fisiológica da estaca é feita principalmente pelo uso de auxinas naturais e sintéticos como o ácido indolbutírico (AIB) e 0 ácido naftalenoacético (ANA) (Zimmerman \& Wilcoxon, 1935). Atualmente, a aplicação de auxinas, principalmente AIB é uma prática comum na multiplicação de plantas frutíferas de interesse agronômico (Junqueira et al., 2006; Mindêllo Neto, 2006; Ribas et al., 2007; Trevisan et al., 2008). Ao passo que, poucos trabalhos são encontrados sobre a propagação vegetativa de espécies florestais (Swamy et al., 2002; Neves et al., 2006; Endres et al., 2007). A presença de folhas nas estacas pode aumentar o seu enraizamento (Breen \& Muraoka, 1974; Reuveni \& Raviv, 1981; Tchoundjeu et al., 2002). Esse fato pode estar correlacionado com o aumento da translocação de carboidratos para a base da estaca (Hansen et al., 1978; Haissig, 1984). No entanto, a produção de auxinas pelas folhas e seu transporte polar em direção a base da estaca parece ser o principal estímulo da presença das folhas sobre 0 seu enraizamento (Breen \& Muraoka, 1974; Tchoundjeu et al., 2002).

O etileno é um dos principais hormônios responsável pela abscisão foliar (Kerbauy, 2004). Segundo Taiz \& Zeiger (2006), a maioria dos efeitos do etileno pode ser antagonizada por inibidores específicos, os principais são tiosulfato de prata (STS), inibidor da síntese de etileno, o aminoethoxi-vinil-glicina (AVG), inibidor da produção do etileno, ambos tendo extraordinário potencial de uso comercial. Trabalhos mostram o uso de inibidores de etileno na abscisão foliar e na formação de raízes em estacas (Bar et al., 1998; Koukounaras et al., 2006). O STS tem sido usado na redução da abscisão foliar em plantas de citros (Bar et al., 1998). O 1-MCP preveniu o amarelecimento e senescência de folhas de rúculas, Eruca sativa Mil, (Koukounaras etal., 2006), brócolos, Brassica oleracea, (Able et al., 2002) e folha de coentro, Coriandrum sativum, (Jiang et al., 2002). Do mesmo modo, o 1-MCP inibiu a abscisão foliar e estimulou a formação de raízes adventícias em Rosa do musgo (Portulaca grandiflora), sugerindo que o etileno interferem na formação de raízes adventícias (Rapaka et al., 2007). Por outro lado, em estudo realizado por Riov \& Yang (2005), com estaquia de feijão mungo (Vigna radiata L.) a interação de AIB (auxina) com AVG revelam a influência de ambos na formação de raízes, sugerem que baixa quantidade de etileno endógeno induz um maior enraizamento.

Outrosfatores podem influenciar oenraizamento com as condições das plantas matrizes, seleção do tipo de estaca, manejo das estacas e controle das condições ambientais durante 0 enraizamento e da época do ano em que são coletadas (Nachtigal 
\& Pereira, 2000). Segundo Fachinello et al. (1995), a época do ano em que as estacas são coletadas está estreitamente relacionada à consistência da estaca, sendo que aquelas coletadas em um período de crescimento vegetativo intenso (primaveral verão), portanto mais herbáceas, tendem a enraizar melhor, enquanto que aquelas coletadas no inverno são mais lignificadas e possuem menor capacidade de enraizamento. Para Rezende (2007) a época ideal para a propagação de cada planta deve ser determinada regionalmente e experimentalmente.

No nordeste Brasileiro, a estação fria pode ser comparada a estação seca, em que as plantas entram em repouso vegetativo. Um estudo mais detalhado sobre a interação entre inibidores da produção e/ou ação do etileno e auxinas sobre o enraizamento de estacas semilenhosas seria de grande interesse para melhorar o processo de propagação vegetativa de espécies florestais e frutíferas ao longo do ano. 0 presente trabalho tem como objetivo avaliar os efeitos dos fitoreguladores ácido indolbutírico (AIB) ou ácido naftalenoacético (ANA) e do inibidor da ação do etileno tiossulfato de prata (STS) sobre o enraizamento de estacas de ingá (Inga fagifolia) coletadas em diferentes épocas do ano.

\section{MATERIAL E MÉTODOS}

Foram coletadas ramos de árvores adultas de Ingá (Inga fagifolia) em bosques do Parque Municipal da cidade de Maceió-AL ("S 09036'33,5" e W $\left.35^{\circ} 45^{\prime} 50,1^{\prime \prime}\right)$ e imediatamente levadas para 0 Laboratório de Botânica da Universidade Federal de Alagoas. Foram coletadas estacas semilenhosas com comprimento entre 8 e 15 centímetros, com 1 ou 2 pares de folhas, posteriormente efetuaram-se o corte na base de cada estaca sempre abaixo de uma gema lateral. Antes da aplicação dos tratamentos, as estacas foram tratadas com o fungicida (Mancozeb $800 \mathrm{~g} \mathrm{~kg}^{-1}$ ) em $3 \mathrm{~g}$ por $100 \mathrm{~mL}$ de água. Foram montados três experimentos em delineamento fatorial. 0 primeiro e segundo experimentos foram realizados durante 0 período de maio a setembro/2005 (época chuvosa). 0 terceiro experimento foi realizado durante o período novembro/2005 a março/2006 (época seca). No primeiro, foram utilizadas três concentrações de STS (0; 0,5; e 2,0 mM) e quatro de concentrações de AIB (0; 12,50; 25 e $50 \mathrm{mM})$. No segundo experimento, a fonte de auxina foi trocada por ANA (0; 12,50; 25 e $50 \mathrm{mM}$ ). Já o terceiro experimento, foi realizado durante a época seca, com os mesmos tratamentos do primeiro experimento (época chuvosa).

As auxinas foram preparadas em balão volumétrico com a diluição de AIB ou o ANA em algumas gotas de $\mathrm{NaOH} \quad 0,5 \mathrm{~N}$ e álcool etílico a $96^{\circ}$, sendo em seguida, completado o volume final com água destilada nas concentrações de 0 ; 12,50; 25 e 50 mM. A solução de tiossulfato de prata (STS) foi preparada conforme Faragher et al. (2002). 6,8 mmoles de tiossulfato de sódio $\left(\mathrm{Na}_{2} \mathrm{~S}_{2} \mathrm{O}_{3}\right.$. $\left.5 \mathrm{H}_{2} \mathrm{O}\right)$ e 64,3 mmoles de nitrato de prata $\left(\mathrm{AgNO}_{3}\right)$ foram dissolvidos em $0,5 \mathrm{~L}$ de água destilada separadamente. Após, as soluções foram misturadas em um balão de 1,0 L formando a solução de $2 \mathrm{mM}$ de tiossulfato de prata. Esta solução foi conservada em frasco escuro na geladeira com temperatura (4 a $8^{\circ} \mathrm{C}$ ). A aplicação de auxinas foi feita por imersão da base da estaca $( \pm 2 \mathrm{~cm})$ por 5 minutos. A aplicação do STS foi feita por pulverização das folhas das estacas até o ponto de escorrimento após a aplicação da auxina. Em seguida, as estacas foram transferidas para o substrato composto de areia em sacos plásticos de polietileno de $2,0 \mathrm{dm}^{3}(2 \mathrm{~L})$. A areia foi lava e esterilizada em estufa a seco a $120^{\circ} \mathrm{C}$ por 48 horas antes de ser usado no experimento. Os sacos de polietileno foram transferidos para uma câmara de nebulização intermitente (casa de vidro), com temperatura em torno de $28^{\circ} \mathrm{C}$ e umidade relativa acima de $90 \%$, controlada com um sensor de umidade automático.

Aos 120 dias da aplicação dos tratamentos, avaliaram-se as porcentagens de estacas sobreviventes, a formação de calo, o enraizamento (emissão de pelo menos uma raiz), número de raízes por estaca, comprimento de raízes e retenção foliar (estaca com folhas).0 delineamento utilizado foi 0 inteiramente casualizado, em esquema fatorial $(3 \times 4)$, sendo os níveis constituídos por três concentrações de STS e quatro concentrações de AIB ou ANA, sendo o primeiro e segundo experimento com três repetições e oito unidades amostrais (estacas) por parcela. E o terceiro experimento com quatro repetições e dez unidades amostrais (estacas) por parcela. Os dados obtidos foram submetidos à análise de variância, pelo teste $F$, e as médias comparadas pelo Teste Tukey a $5 \%$ de probabilidade. 


\section{RESULTADOS}

O AIB teve efeito inibitório sobre o enraizamento de estacas de ingá em ambas as épocas de estaquia (Figura $1 \mathrm{~A}$ e $1 \mathrm{~B}$ ). $\mathrm{A}$ maior taxa de enraizamento foi encontrada, na época chuvosa, no tratamento controle com $66,7 \%$ de estacas enraizadas, reduzindo para menos de $12 \%$ quando aplicado $50 \mathrm{mM}$ de AIB. $\mathrm{Na}$ época seca, o máximo de enraizamento foi de $35,8 \%$ no tratamento controle, reduzindo para $7,7 \%$ quando aplicado $50 \mathrm{mM}$ de AIB. Por outro lado, o ANA parece ter pouco efeito sobre o enraizamento das estacas, apresentando taxa entre 55 e 75\% (Figura 1C). Em outras espécies, a aplicação de auxina também inibiu o enraizamento com em jambeiro-rosa (Syzygium Malacensis L. Merr. \& Perry) (Martins et al., 2001). Estacas de pau-brasil (Caesalpina echinata Lam.) a aplicação de AIB acima de 2,5 mM não estimulou 0 enraizamento (Endres et al., 2007). Já Lima et al. (2008) observaram que a aplicação de AIB e ANA não apresentou efeitos positivos na taxa de enraizamento de espinheira-santa (Maytenus ilicifolia). As concentrações excessivas de auxinas podem ser prejudiciais causando amarelecimento, perda foliar, escurecimento de caule e, eventualmente morte das estacas (Hartmann et al., 1997).
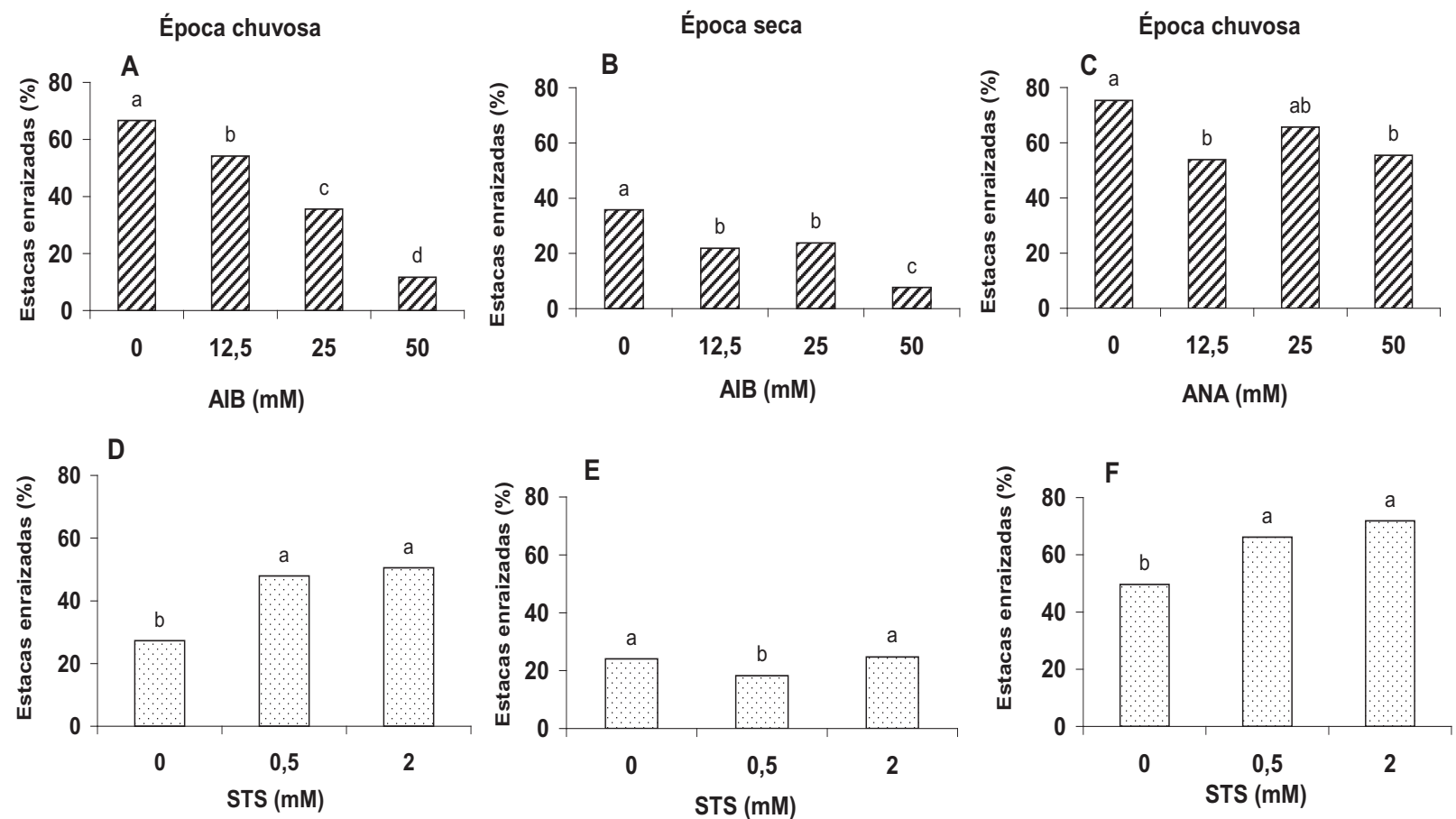

FIGURA 1. Efeito do fitorregulador (A, B, C) e tiossulfato de prata (C, D, E) sobre enraizamento de estacas de ingá (Inga fagifolia), coletadas no mês de maio de 2005 (época chuvosa) e novembro de 2005 (época seca). Avaliação aos 120 dias após o estaqueamento em Maceió-AL. Diferentes Médias seguidas das mesmas letras, não diferem entre si pelo teste de Tukey a $5 \%$.

Com relação às épocas de coleta $e$ estaqueamento, verificou-se que na época seca ocorreu uma baixa taxa de enraizamento, com valores maiores de $36 \%$ naausência de auxinas (Figura 1B). O porcentual de enraizamento do ingá nessa época foi em torno de $50 \%$ menor quando comparados à época chuvosa para variável sobrevivência e estacas enraizadas (Tabela1). Isso demonstra que a resposta ao enraizamento das estacas pode diferir entre as épocas dos anos, sugerindo que as altas temperaturas e baixas precipitações desse período possam ter contribuído para baixa umidade do ambiente, influenciando negativamente no desenvolvimento das estacas. Segundo Pasqual et al. (2001), a umidade alta é um dos fatores externo fundamentais para ocorrer enraizamento das estacas. Além disso, estacas menos lignificadas (herbáceas e semilenhosas) são mais propícias a desidaratação e a morte (Hartmann et al., 1997). De acordo com Dutra et al. (2002), a influência da época de coleta das estacas no enraizamento pode ser também atribuída às condições climáticas, especialmente no que se refere à temperatura e à disponibilidade de água. Trevisan et al. (2008), trabalhando com estacas herbáceas mirtilo (Vaccinium sp.) na época seca (verão), verificou 
baixo porcentual de enraizamento nesse período, sugerindo que vários fatores podem ter influenciado como a pouca precipitação pluviométrica, interferindo assim na condição fisiológica da planta matriz, no teor de reservas e de nutrientes. Por outro lado, diversos autores constataram que durante a primavera/verão são encontrados os maiores percentuais de enraizamento de estacas em diferentes espécies (Mayer et al., 2001; Dutra et al., 2002; Castro \& Silveira, 2003; Carvalho et al., 2005).

TABELA 1- Porcentagens de estacas enraizadas, número médio de raízes por estacas e comprimento de raízes (cm) em estaca de ingá (Inga fagifolia), em função das concentrações de auxinas e tiosulfato de prata (STS), coletadas em duas épocas distintas, mês de maio de 2005 (época chuvosa) e novembro de 2005 (época seca), avaliadas aos 120 dias após a estaquia, UFAL, Maceió-AL, 2006.

\begin{tabular}{|c|c|c|c|c|c|}
\hline \multicolumn{6}{|c|}{$\begin{array}{c}\text { Época chuvosa } \\
\text { Estacas enraizadas (\%) }\end{array}$} \\
\hline \multicolumn{6}{|c|}{$\mathrm{AIB}(\mathrm{mM})$} \\
\hline STS (mM) & 0,0 & 12,5 & 25 & 50 & Média \\
\hline 0,0 & $37,50^{b}$ & $31,26^{b}$ & $21,80^{b}$ & $18,60^{\mathrm{a}}$ & $27,30^{\mathrm{b}}$ \\
\hline 0,5 & $75,00^{a}$ & $62,50^{\mathrm{a}}$ & $50,00^{a}$ & $4,16^{a}$ & $47,91^{a}$ \\
\hline 2,0 & $85,50^{a}$ & $68,76^{a}$ & $33,33^{a b}$ & $12,50^{\mathrm{a}}$ & $50,52^{\mathrm{a}}$ \\
\hline Média & $66,66^{A}$ & $54,17^{\mathrm{B}}$ & $35,04^{C}$ & $11,70^{\circ}$ & \\
\hline CV (\%) & & & & & 22,47 \\
\hline \multicolumn{6}{|c|}{$\begin{array}{c}\text { Época seca } \\
\text { Estacas enraizadas (\%) }\end{array}$} \\
\hline \multicolumn{6}{|c|}{$\mathrm{AIB}(\mathrm{mM})$} \\
\hline STS (mM) & 0,0 & 12,5 & 25 & 50 & Média \\
\hline 0,0 & $35,00^{a}$ & $20,25^{a}$ & $27,80^{a}$ & $13,25^{a}$ & $24,04^{a}$ \\
\hline 0,5 & $33,20^{\mathrm{a}}$ & $21,60^{a}$ & $10,55^{\mathrm{a}}$ & $7,50^{\mathrm{a}}$ & $18,24^{b}$ \\
\hline 2,0 & $39,30^{a}$ & $29,80^{\mathrm{a}}$ & $33,12^{\mathrm{a}}$ & $2,50^{a}$ & $27,70^{a}$ \\
\hline Média & $35,80^{A}$ & $21,90^{B}$ & $23,80^{\mathrm{B}}$ & $7,7^{\mathrm{C}}$ & \\
\hline CV (\%) & & & & & 22,27 \\
\hline
\end{tabular}

\begin{tabular}{rrrrl}
\hline \multicolumn{5}{c}{$\begin{array}{c}\text { Época chuvosa } \\
\text { Número médio de raízes/estaca } \\
\text { AIB (mM) }\end{array}$} \\
\hline 0,0 & 12,5 & 25 & 50 & Média \\
\hline $4,46^{\mathrm{b}}$ & $10,56^{\mathrm{b}}$ & $3,50^{\mathrm{b}}$ & $20,51^{\mathrm{a}}$ & $9,76^{\mathrm{b}}$ \\
$9,33^{\mathrm{a}}$ & $33,00^{\mathrm{a}}$ & $22,00^{\mathrm{a}}$ & $5,00^{\mathrm{b}}$ & $17,33^{\mathrm{a}}$ \\
$3,66^{\mathrm{b}}$ & $15,00^{\mathrm{b}}$ & $25,66^{\mathrm{a}}$ & $15,66^{\mathrm{ab}}$ & $15,00^{\mathrm{ab}}$ \\
\hline $5,81^{\mathrm{B}}$ & $19,52^{\mathrm{A}}$ & $17,05^{\mathrm{A}}$ & $13,73^{\mathrm{A}}$ \\
& & & & 37,28 \\
\hline
\end{tabular}

\begin{tabular}{|c|c|c|c|c|}
\hline \multirow{2}{*}{\multicolumn{5}{|c|}{$\begin{array}{c}\text { Época chuvosa } \\
\text { Comprimento de raízes }(\mathrm{cm}) \\
\operatorname{AIB}(\mathrm{mM})\end{array}$}} \\
\hline & & & & \\
\hline 0,0 & 12,5 & 25 & 50 & Média \\
\hline $14,33^{a}$ & $12,50^{\mathrm{a}}$ & $17,46^{a}$ & $84,46^{a}$ & $32,24^{a}$ \\
\hline $17,33^{\mathrm{a}}$ & $16,00^{a}$ & $18,00^{\mathrm{a}}$ & $5,33^{b}$ & $14,16^{b}$ \\
\hline $15,00^{\mathrm{a}}$ & $16,66^{a}$ & $15,00^{\mathrm{a}}$ & $9,00^{b}$ & $13,91^{\mathrm{b}}$ \\
\hline $15,62^{\mathrm{B}}$ & $15,05^{\mathrm{B}}$ & $16,82^{B}$ & $32,93^{A}$ & \\
\hline & & & & 24,91 \\
\hline
\end{tabular}

Número médio de raízes/estaca

Época seca

Comprimento de raízes $(\mathrm{cm})$

$\mathrm{AIB}(\mathrm{mM})$

\begin{tabular}{rrrrr}
\hline 0,0 & 12,5 & 25 & 50 & Média \\
\hline $3,82^{\mathrm{a}}$ & $14,15^{\mathrm{a}}$ & $28,97^{\mathrm{a}}$ & $17,12^{\mathrm{b}}$ & $16,02^{\mathrm{a}}$ \\
$5,80^{\mathrm{a}}$ & $25,50^{\mathrm{a}}$ & $11,75^{\mathrm{b}}$ & $23,80^{\mathrm{a}}$ & $16,96^{\mathrm{a}}$ \\
$9,35^{\mathrm{a}}$ & $18,82^{\mathrm{a}}$ & $12,87^{\mathrm{b}}$ & $8,80^{\mathrm{b}}$ & $11,01^{\mathrm{a}}$ \\
\hline $5,00^{\mathrm{B}}$ & $19,49^{A}$ & $17,85^{\mathrm{A}}$ & $16,30^{\mathrm{A}}$ & \\
& & & & 51,87 \\
\hline
\end{tabular}

Época chuvosa
Estacas enraizadas $(\%)$

ANA(mM)

Número médio de raízes/estaca

ANA (mM)

\begin{tabular}{crrrcc}
\hline STS (mM) & 0,0 & 12,5 & 25 & 50 & Média \\
\hline 0,0 & $53,16^{\mathrm{b}}$ & $40,66^{\mathrm{b}}$ & $71,90^{\mathrm{a}}$ & $32,86^{\mathrm{b}}$ & $49,65^{\mathrm{b}}$ \\
0,5 & $81,26^{\mathrm{a}}$ & $50,00^{\mathrm{ab}}$ & $62,52^{\mathrm{a}}$ & $70,83^{\mathrm{a}}$ & $66,15^{\mathrm{a}}$ \\
2,0 & $91,33^{\mathrm{a}}$ & $70,83^{\mathrm{a}}$ & $62,52^{\mathrm{a}}$ & $62,50^{\mathrm{a}}$ & $71,87^{\mathrm{a}}$ \\
\hline Média & $75,36^{\mathrm{A}}$ & $53,83^{\mathrm{B}}$ & $65,65^{\mathrm{AB}}$ & $55,44^{\mathrm{B}}$ & \\
CV (\%) & & & & & 18,30 \\
\hline
\end{tabular}

\begin{tabular}{rrrrr}
\multicolumn{5}{c}{ ANA (mM) } \\
\hline 0,0 & 12,5 & 25 & 50 & Média \\
\hline $3,50^{\mathrm{b}}$ & $16,93^{\mathrm{a}}$ & $28,53^{\mathrm{a}}$ & $32,46^{\mathrm{a}}$ & $20,36^{\mathrm{a}}$ \\
$5,00^{\mathrm{b}}$ & $11,00^{\mathrm{ab}}$ & $5,33^{\mathrm{b}}$ & $3,66^{\mathrm{b}}$ & $6,25^{\mathrm{C}}$ \\
$34,66^{\mathrm{a}}$ & $5,00^{\mathrm{b}}$ & $8,66^{\mathrm{b}}$ & $3,33^{\mathrm{b}}$ & $12,91^{\mathrm{b}}$ \\
\hline $14,38^{\mathrm{A}}$ & $10,97^{\mathrm{A}}$ & $14,17^{\mathrm{A}}$ & $13,15^{\mathrm{A}}$ & \\
& & & & 31,10 \\
\hline
\end{tabular}

\begin{tabular}{rrrrr}
\multicolumn{5}{c}{ AIB (mM) } \\
\hline 0,0 & 12,5 & 25 & 50 & Média \\
\hline $15,32^{\mathrm{a}}$ & $10,87^{\mathrm{a}}$ & $13,75^{\mathrm{a}}$ & $9,50^{\mathrm{a}}$ & $12,53^{\mathrm{a}}$ \\
$17,72^{\mathrm{a}}$ & $19,70^{\mathrm{a}}$ & $20,50^{\mathrm{a}}$ & $15,42^{\mathrm{a}}$ & $18,33^{\mathrm{a}}$ \\
$25,35^{\mathrm{a}}$ & $15,75 \mathrm{a}$ & $17,55^{\mathrm{a}}$ & $7,70^{\mathrm{a}}$ & $17,11^{\mathrm{a}}$ \\
\hline $20,13^{\mathrm{A}}$ & $15,75^{\mathrm{AB}}$ & $17,30^{\mathrm{AB}}$ & $10,91^{\mathrm{B}}$ & \\
& & & & 38,10 \\
\hline
\end{tabular}

Época chuvosa

Comprimento de raízes $(\mathrm{cm})$ ANA (mM)

\begin{tabular}{crrrr}
\hline 0,0 & 12,5 & 25 & 50 & Média \\
\hline $15,06^{\mathrm{a}}$ & $12,43^{\mathrm{a}}$ & $17,46^{\mathrm{a}}$ & $18,36^{\mathrm{a}}$ & $15,83^{\mathrm{a}}$ \\
$15,66^{\mathrm{a}}$ & $15,00^{\mathrm{a}}$ & $29,33^{\mathrm{a}}$ & $14,33^{\mathrm{a}}$ & $18,58^{\mathrm{a}}$ \\
$19,33^{\mathrm{a}}$ & $16,33^{\mathrm{a}}$ & $31,00^{\mathrm{a}}$ & $18,00^{\mathrm{a}}$ & $21,16^{\mathrm{a}}$ \\
\hline $16,68^{A B}$ & $14,58^{\mathrm{B}}$ & $25,93^{\mathrm{A}}$ & $16,90^{A B}$ & \\
& & & & 43,78 \\
\hline
\end{tabular}

* Para avaliação dos efeitos de STS, médias dentro da mesma coluna, seguidas pelas mesmas letras minúsculas e para avaliar efeitos de AIB ou ANA, médias dentro da mesma linha, seguidas por letras maiúsculas, não diferem estatisticamente entre si ao nível de $5 \%$ de probabilidade pelo teste de Tukey.

Quando analisado o efeito do STS independente das doses de auxinas foi verificado nos tratamentos realizados na época seca que mantiveram menores porcentagens de estacas enraizadas (Figura 1E). Foi observado também que o STS aumenta a taxa de enraizamento em concentrações superiores da 0,5 mM (Figura 1D e 1F), discordando de dados encontrados por Tanimoto et al. (1995), que verificaram a inibição da formação de calo e raízes em mudas de Arabidopsis (Arabidopsis thaliana) tratadas com AVG ou STS. Outro estudo apresentado por Jusaitis (1986) em feijão- de-mungo (Vigna radiata L.) revelou que inibidores da síntese de etileno, como AVG aumentam a taxa de estacas enraizadas, seguindo a hipótese que a baixa concentração de etileno endógeno é eficaz na formação de raízes. No entanto, essas espécies são bastante herbáceas, portanto bem mais propensas a dediferenciação celular que leva a formação de calos e raízes, portanto doses e tempo de exposição de reguladores de crescimento muito baixos são requeridos para induzir os efeitos fisiológicos, ao contrário do ingá que é uma espécie semilenhosa. 
O STS teve efeito interativo com as doses de AIB e ANA segundo análise de variância independente da época de coleta. O STS teve um efeito significativo sobre o enraizamento das estacas na ausência de auxina (Tabela 1). 0 aumento da concentração de AIB e ANA fez com que essa diferença diminuísse e até foi revertida com $50 \mathrm{mM}$ de AIB, ou seja, a alta concentração de STS e AIB tiveram um efeito sinergístico sobre a inibição do enraizamento. Resultados semelhantes foram encontrados por Riov \& Yang (2005) que verificaram que altas concentrações de AIB e AVG reduziram o enraizamento de estacas de feijão mungo (Vigna radiata L.).

No final do experimento, todas as estacas sobreviventes apresentam folhas e tinham formação de calos e raízes, por isso na Tabela 1 somente são apresentados os dados de estacas enraizadas. Esses dados levam a sugerir que a presença de folhas nas estacas é importante para a sua sobrevivência e a formação de calos e raízes. A importância das folhas para o enraizamento já foi demonstrada na estaquia de goiabeira, Psidium guajava L. (Pereira et al., 1983), em abacateiro, Persea americana Mill. (Reuveni \& Raviv, 1981) e em figueira, Ficus carica L. (Pio et al., 2004). 0 efeito benéfico da presença das folhas em estacas semilenhosas pode ser atribuído pela continuação do processo de fotossíntese, responsável pela síntese de carboidratos necessários como fonte de energia para formação e crescimento das raízes (Haissig, 1984).

O AIB estimulou a formação de raízes adventícias nas estacas nas duas épocas (Tabela 1). Na menor concentração de AIB obteve-se o maior número de raízes por estacas, diminuindo nas concentrações maiores, embora de maneira não significativa. Por outro lado, o ANA não teve efeito sobre a formação de raízes. O STS teve efeito ambíguo sobre a formação de raízes, não havendo uma tendência clara de seu efeito sobre o número de raízes. Esses resultados concordam com Bastos et al. (2006) que observaram que o aumento da concentração de AIB fez com que diminuísse a resposta no enraizamento de estacas de lichieira (Litchi chinensis Soon.). Entretanto, Silva et al. (1986), trabalhando com enraizamento de estacas de videira (Vitis vinifera L.), verificaram que o AlB agiu aumentando o número de raízes, o que também foram observados por Mayer et al. (2001) em estacas hebácia de umezeiro (Prunus mume Sieb \& Zucc.), que notaram um aumento no número de raízes em estacas submetido a auxinas.

O comportamento do tamanho de raiz se mostrou bastante variável entre os tratamentos (Tabela 1). $O$ comprimento médio de raízes apresentou melhor resultado na concentração $50 \mathrm{mM}$ de AIB na época chuvosa; na aplicação de ANA, o comprimento médio das raízes foi maior na concentrações de $25 \mathrm{mM}$ (Tabela 1). Com relação o comprimento médio das raízes na época seca foi maior na concentrações de 25 $\mathrm{mM}$ de AIB. Em estacas herbácea de umezeiro, Prunus mume Sieb \& Zucc. (Mayer et al., 2001) e em estacas semilenhosas de pessegueiro, Prunus pérsica. (Ribas et al., 2007) os autores verificaram que 0 uso do AIB também proporcionou um aumento no comprimento de raízes. Já Martins et al. (2001) em trabalho com estacas de jambeiro-rosa (Syzygium malacensis) e Endres et al. (2007) em pau-brasil (Caesalpina echinata Lam.), constataram que não houve efeito significativo de qualquer tratamento utilizando AIB no comprimento médio das raízes.

\section{CONCLUSÕES}

0 ácido indolbutírico (AIB) em todas as doses testadas, entre 12,5 e $50 \mathrm{mM}$, inibiu o enraizamento.

0 ácido naftalenoacético (ANA) até a concentração de $50 \mathrm{mM}$ não teve efeito sobre 0 enraizamento.

Doses acima de 0,5 mM de STS na ausência de auxina foram mais eficientes no enraizamento de estacas, talvez por aumentar a retenção foliar, o qual deve ser considerado como base para novos estudos envolvendo propagação por estaquia.

A época mais favorável para a estaquia correspondeu ao mês de maio (época chuvosa).

\section{REFERÊNCIAS BIBLIOGRÁFICAS}

ABLE, A. J.; WONG, L. S.; PRASAD, A.; HARE, T. 1-MCP is more effective on a floral brassica (Brassica oleracea var. italica $\mathrm{L}$ ) than a leafy brassica (Brassica rapa var. chinensis). Postharvest Biology and technology, 26, n. 2, p. 147-155, 2002.

BAR. Y.; APELBAUM, A.; KAFKAFI, U.; GOREN, R. Ethylene association with chloride stress incitrus plants. Scientia Horticultura, v. 73, n. 2, p. 99-109, 1998. 
BASTOS, D. C.; PIO, R.; SCARPARE FILHO, J. A.;ALMEIDA, L. F. P. de, ENTELMANN, F. A.; ALVES, A. S. R. Tipo de estacas e concentração de ácido indobultirico na propagação da lichieira. Ciências agrotecnica, v. 30, n. 1, p. 97-102, 2006.

BREEN, P. J.; MURAOKA, T. Effect of leaves and carbohydrate content and movement of $\mathrm{C}$-assimilate in plum cuttings. Journal of the American Society for Horticultural Science, v. 99, p. 326-332, 1974.

CARVALHO, C. M.; CUNHA, R. J. P.; RODRIGUES, J.D. Enraizamento de estacas semilenhosas de lichieira utilizando ácido indolbutírico. Revista Brasileira de Fruticultura, v. 27, n. 1, p. 95-97, 2005.

CASTRO, L. A. S.; SILVEIRA, A. P. Propagação vegetativa do pessegueiro por alporquia. Revista Brasileira de Fruticultura, v. 25, n. 2, p. 368-370, 2003.

DONADIO, L. C.; MARTINS, A. B. G.; VALENTE, J. P. Fruticultura tropical. Jaboticabal: FUNEP, 1992. 268p.

DUTRA, L. F.; KERSTEN. E.; FACHINELLO, J. C. Época de coleta, ácido indolbutírico e triptofano no enraizamento de estacas de pessegueiro. Scientia Agricola, v. 59, n. 2, p. 327-333, 2002.

ENDRES, L.; MARROQUIM, P. M. G; SANTOS, C. M.; SOUZA, N. N. F. Enraizamento de estacas de paubrasil (Caesalpina echinata Lam.) tratadas com ácido indolbutírico e ácido naftaleno acético. Revista ciências rural, Santa Maria, v. 37, n. 3, p. 886-889, 2007.

FACHINELLO, J. C. FACHINELLO, J. C.; HOFFMANN, A.; NACHTIGAL, J. C.; KERSTEN, E. Propagação de plantas frutíferas de clima temperado. 2.ed. Pelotas: UFPEL, 1995. $178 \mathrm{p}$.

FARAGHER, J.; GOLLNOW, B.; JOYCE, D. Postharvest handling of Australian flowers - from Australian native plants and related species: a pratical. Victoria: RIRDC, 2002. 215 p.

FRANCIS, J. K. Inga fagifolia (L.) Willd. Guamá. New Orleans, LA: U.S. Department of Agriculture, 1994. 4 p.

HAISSIG, B. E. Carbohydrate accumulation and partitioning in Pinus banksiana seedling an seedling cutting. Plant Physiology, v. 61, p. 13-19, 1984.
HANSEN, J.; STROEMQUIST, L. I. I.; ERICSSON, A. Influence of the irradiance on carbohydrate content and rooting of cutting of pin seedling (Pinus sylvestris L.). Plant Physiology, v. 61, p. 975-979, 1978.

HARTMANN, H. T.; KESTER, D. E.; DAVIES, F. T. Jr.; GENEVE, R. L. Plant propagation: principles and practices. $6^{\circ}$ ed. Prentice-Hall: New Jersey, 1997. 720 p.

JIANG, W.; SHENG, Q.; ZHOU, X.; ZHANG, M.; LIU, $X$. Regulation of detached coriander leaf senescence by 1-methylcyclopropene and ethylene. Postharvest Biology and Technology, v. 26, p. 339-345, 2002.

JUSAITIS, M. Rooting of intact mung bean hypocotyls stimulated by auxin, ACC, and low temperature. HortScience, v. 21, p. 1024-1025, 1986.

JUNQUEIRA, N. T. V.; LAGE, D. A. C.; BRAGA, M. F. PEIXOTO; J. R., BORGES; T. A., ANDRADE; S. R. M. de . Reação a doenças e produtividade de um clone de maracujazeiro azedo propagado por estaquia e enxertia em estacas herbáceas de passiflora silvestre. Revista Brasileira de Fruticultura, v. 28, n. 1, p. 97-100, 2006.

KERBAUY, G. B. Fisiologia Vegetal. Rio de Janeiro: Guanabara Koognsa, 2004. 452 p.

KOUKOUNARAS, A.; SIOMOS, A. S.; SFAKIOTAKIS, E. Methylcyclopropene prevents ethylene induced yellowing of rocket leaves. Postharvest Biology and Technology, v.41, p.109-111, 2006.

LITTLE JR, E. L.; WADSWORTH, F. H. Common trees of Puerto Rico and the Virgin Islands. Agric Handb. Washington, DC: U.S. Department of Agriculture. 1964, $548 \mathrm{p}$.

LIMA, D. M.; SILVA, C. L.; RITTER, M.; BIASI, L. A.; ZANETTE, F.; ZUFFELLATO-RIBAS, K. C. Substratos e auxinas no enraizamento de estacas caulinares de espinheira-santa. Scientia Agraria, v. 9, n. 1, p. 85-89, 2008.

LOPES, K.P. BRUNO, R. de L.A.; BRUNO, G.B.; MOURA, M.F. Comportamento de Sementes de Inga sp. Durante o Armazenamento. In: XVII Congresso Brasileiro de Fruticultura, 2002, Belém. Os Novos Desafios da Fruticultura Brasileira, 2002. 
LORENZI, H. Árvores brasileiras: manual de identificação e cultivo de plantas arbóreas nativas do Brasil. Vols. 1 e 2, $4^{a}$ edição. Nova Odessa, SP: Plantarum, 2004. 348 p.

MAYER, N. A.; PEREIRA, F. M.; NACHTIGAL, J. C. Propagação do umezeiro (Prunus mume Sieb \& Zucc.) por estaquia herbácea. Revista Brasileira de Fruticultura, v. 23, n. 3, p. 673-676, 2001.

MARTINS, A. B. G.; GRACIANO, F. A.; SILVA, A. V. C. Clonagem do Jambeiro - Rosa (Syzygium malacensis) por estaquia de ramos enfolhados. Revista Brasileira de fruticultura, v. 23, n.2, p. 365-368, 2001.

MINDÊLLO NETO, U. R. Estaquia herbácea de pessegueiro cv. Charme, em função de diferentes concentrações de ácido indolbutírico (aib) e número de folhas. Revista Brasileira Agrociência, v. 12, n. 1, p. 27-29, 2006.

NACTHIGAL, J. C.; PEREIRA, F.M. Propagação do pessegueiro (Prunus persica (L.) Batsch) cv. Okinawa por meio de estacas herbáceas em câmara de nebulização em Jaboticabal - SP. Revista Brasileira de Fruticultura, v. 22, n. 2, p. 208-212, 2000.

NEVES, T. S.; CARPANEZZI, A. A.; ZUFFELLATORIBAS, K. C.; MARENCO, R. A. Enraizamento de corticeira-da-serra em função do tipo de estaca e variações sazonais. Pesquisa agropecuária brasileira, v. 41, n. 12, p. 1699-1705, 2006.

OLIVEIRA, D. M. T.; BELTRATI, C. M. Aspectos anatômicos de frutos e sementes em Inga fagifolia Willd. (Fabaceae:Mimosoideae). Revista Brasileira de Biologia, v. 53, n. 4, p. 625-636, 1993.

PASQUAL, M.; CHALFUN, N. N. J.; RAMOS, J.D.; VALE, M. R. do; SILVA, REZENDE e SILVA, C. R. de. Fruticultura comercial: Propagação de plantas frutíferas. Lavras: UFLA/FAEPE, 2001. 137 p.

PEREIRA, F. M.; OIOLI, A. A. P.; BANZATTO, D. A. enraizamento de diferentes tipos de estacas enfolhadas de goiabeira (Psidium guayava L.) em câmaras de nebulização. Cientifica, v.11, n. 2, p.139244, 1983.
PIO, R.; CHALFUN, N. N. J.; RAMOS, J. D.; GONTIJO, T. C. A.; TOLEDO, M.; CARRIJO, E. P. Presença de folhas e gema apical no enraizamento de estacas herbáceas de figueira oriundas da desbrota. Revista brasileira de Agrociência, v. 10, n. 1, p. 51-54, 2004.

RAPAKA, V. K.; FAUST, J. E.; DOLE, J. M.; Runkle, E. $S$. Diurnal carbohydrate dynamics affect postharvest ethylene responsiveness in portulaca (Portulaca grandiflora 'Yubi Deep Rose') unrooted cuttings, Postharvest Biology and Technology, v. 44, p. 293299, 2007.

REUVENI, O.; RAVIV, M. Importance of leaf retention to rooting avocado cuttings. Journal of the American Society for Horticultural Science, v. 106, p.127-130, 1981.

REZENDE, A. A. Enraizamento de estacas de candeia (Eremanthus eryhropappus DC.). 2007. 75p. Dissertação (Mestrado em Engenharia Florestal). Departamento de Ciências florestais da Universidade Federal de Lavras, Lavras, Minas Gerais.

RIBAS, C. P.; GOMES, F. G. D.; LEONOR, R.; BIASI, L. A.; MARÇALLO, F. A. Ácido indolbutírico no enraizamento de estacas semilenhosas das cultivares de pessegueiro della nona e eldorado. Scientia Agraria, v.8, n.4, p.439-442, 2007.

RIOV, J.; YANG, S. F. Ethylene and auxin-ethylene interaction in adventitious root formation in mung bean (Vigna radiata) cuttings. Journal of Plant Growth Regulation, v. 8, n. 2, p. 131-14, 2005.

SILVA, A. L.; FACHINELLO, J. C.; MACHADO, A. A. Efeito do ácido indolbutírico na enxertia e enraizamento da videira. Pesquisa Agropecuária Brasileira, v. 21, p. 864-71, 1986.

SWAMY, S. L.; PURY, S.; SINGH, A. K. Effect of auxins (IBA and NAA) and season on rooting of juvenile and mature hardwood cutting of Robinia pseudoacacia and Grewia optiva. New Forests, v. 23, p. 143-157, 2002.

TAIZ, L.; ZEIGER, E. Fisiologia Vegetal 3 ed. Porto Alegre: Editora Artmed, 2006. 219p. 
TANIMOTO, M.; ROBERTS, K.; DOLAN, L. Ethylene is a positive regulator of root hair development in Arabidopsis thaliana. Plant Jornal, v. 8, p. 943-948, 1995.

TCHOUNDJEU, Z.; AVANA, M. L.; LEAKEY, R. R. B.; SIMONS, A. J.; ASSAH, E.; DUGUMA, B.; BELL, J. M. Vegetative propagation of Prunus africana: effects of rooting médium, auxin concentrations and leaf area.

Agroforestry Systems, v. 54, p. 183-192, 2002.
TREVISAN, R.; FRANZON, R. C.; FRITSCHENETO, R.; GONÇALVES, R. S.; GONÇALVES, E. D.; ANTUNES, L. E. C. Enraizamento de estacas herbáceas de mirtilo: influência da lesão na base e do ácido indolbutírico. Ciências agrotecnica, v. 32, n. 2, p. 402-406, 2008.

ZIMMERMAN, P. W.; WILCOXON, F. Several chemical growth substances, which cause initiation of root and other responses in plants. Contributions from Boyce Thompson Institute, v.7, p. 209-229, 1935. 